(C) 2012 IEEE. Personal use of this material is permitted. Permission from IEEE must be obtained for all other uses, in any current or future media, including reprinting/republishing this material for advertising or promotional purposes, creating new collective works, for resale or redistribution to servers or lists, or reuse of any copyrighted component of this work in other works. 


\title{
Economic Analyses of Plug-in Electric Vehicle Battery Providing Ancillary Services
}

\author{
Zhuowei Luo, Student Member, IEEE, Zechun Hu, Member, IEEE, Yonghua Song, Fellow, IEEE, \\ Zhiwei Xu, Student Member, IEEE, Hui Liu, Long Jia , Student Member, IEEE and Haiyan Lu \\ Member, IEEE
}

\begin{abstract}
This paper explores the potential financial return for using plug-in electric vehicles (PEVs) as a grid resource. There are two methods for PEVs to provide ancillary services call interruptible load and vehicle to grid The contract market is introduced first, then the method to calculate the cost benefit of plug-in electric vehicles (PEVs) to provide ancillary services are proposed. Additionally, the expected profits and profits of providing the ancillary services when considering the uncertainties of driving behaviors are both calculated and compared. The calculation results indicate that profits of participating in frequency regulation are higher than that of reserve services. When penalty is neglected or the penalty coefficient is low, the revenue of regulation down services is relatively high. However, with the increasing of penalty factor, the profits decrease dramatically. When the penalty coefficient is sufficiently high, participating in regulation up services in V2G mode is most profitable.
\end{abstract}

Index Terms - Plug-in electric vehicles (PEV), Cost-benefit analysis, Ancillary services, Interruptible load, Vehicle to grid (V2G).

\section{INTRODUCTION}

$\mathrm{W}$ ith the development of automobile industry, the wide adoption of internal combustion engine based vehicle causes severe energy shortage, environment pollution and global warming. Therefore the transformation of automobile industry is unavoidable. Recently, the development of electric vehicles has drawn extensive attentions globally.

Optimally controlling the charging and discharging of electric vehicles can effectively alleviate the negative impacts on power system and improve the security and economy of the system. The cost and benefit analysis, which acts as the foundation to attract the participation of electric vehicle owners in grid control, have drawn extensive attentions. Back in 1997, Kempton has introduced the notion of vehicle to grid (V2G) in [1]. Additionally, the feasibility of V2G [2] [3] and its potential benefits [4] [5] have been further studied. Compared with the traditional power sources, the electric vehicles have characteristics of lower energy, higher electricity costs and quick response time. It is applicable for the cases of high capacity prices, short duration time and high demand on quick response time. The services provided by electric vehicles mainly focus on frequency regulation, spinning reserve and peak load shaving [2]-[5]. References [6] and [7] investigate the cost and benefit of electric vehicles participation in frequency regulation and peak load shaving services.

In [1]-[7], profits of electric vehicle owners who provide the ancillary services (A/S) are mainly based on the average values of driving behavior. For example, the daily plugged-in time duration of each vehicle is 23 hours in [5]. However, the driving behavior of each vehicle is highly uncertain. The actual time for each vehicle to participate in the $\mathrm{A} / \mathrm{S}$ is quite different. The contract signed between the grid and the PEV owner may be violated in some cases. Therefore the behaviors of users should be monitored. To the authors' knowledge, the plug-in electric vehicles (PEVs) act as the interruptible load (IL) to provide the $\mathrm{A} / \mathrm{S}$ is not mentioned. This paper investigates the profits of electric vehicles users to provide $\mathrm{A} / \mathrm{S}$ in different modes when the uncertainties of driving behaviors are considered. The regulation services are divided into two categories which are regulation up and regulation down. The IL and V2G patterns to provide regulation up and spinning reserve services are presented. The penalty cost in terms of the contract violation is also investigated.

In the following parts of this paper, the mechanisms of the contract market are analyzed first, then the modes of PEVs to provide A/S are analyzed. Additionally, the cost and benefit calculation method including penalty cost are investigated. The revenue of PEV owners to provide $\mathrm{A} / \mathrm{S}$ in different modes is calculated both with the expected values and considering the uncertainties. Furthermore, the sensitivity analyses are carried on annual revenue to penalty coefficient. The results indicate that the actual revenue of electric vehicles owners is less than the expected value when uncertainties are considered.

\section{RESEARCH BASIS}

\section{A. Contract market}

Before the launch of the frequency regulation and spinning reserve services, a contract would be made between the grid and vehicle owners. The contract would confirm the amount of the power capacity and the time period for the PEV providing A/S. During the contract hours, the PEV would supply power to or draw power from the grid to follow the commands from the grid operator. The commands should be within the contracted power capacity (CPC). Consequently, the customer would confirm their available power capacity and the time period to sign a contract with the grid operator. The more capacity and longer time period signed, the more payment the PEV owner will receive. With higher CPC and longer contracted time period (CPT), however, it becomes more vulnerable in terms of fulfilling the contract because of uncertainties of daily driving behavior. 


\section{B. The modes of PEVs to provide the $A / S$}

In this paper, we will calculate the revenue of PEV to provide the regulation services and the spinning reserve services which are the best match of PEVs to electric markets. The revenue of regulation up and regulation down are calculated separately. There are two basic modes for PEVs to provide regulation up and spinning reserve services, which are the IL and V2G. The PEV should be charging continuously during the CTP in IL mode, and stop charging to respond the grid command. As a result, the charging power of PEV is relatively low in IL mode. The PEVs act as controllable distributed energy storage units in the V2G pattern. PEV can be charging and discharging at rated power capacity to gain more revenue.

To provide regulation down services, the PEVs ought to increase charging power to satisfy the grid needs. Once the PEVs are fully charged, they can't provide regulation down services. As a result, it is reasonable to assume that the PEVs will not fill the battery immediately when they plugged in. A specified period will be reserved before prenotified departure time to fill the battery.

\section{COST AND BENEFIT OF PEVS PROVIDE ANCILLARY SERVICES}

\section{A. Calculation of the cost}

The total annual cost $C$ is composed of fixed annual cost for the maintenance and infrastructure investment, variable cost due to energy cost and battery degradation, and penalty cost from the grid. It can be calculated by:

$$
\begin{aligned}
& C=C_{f}+C_{\mathrm{var}}+C_{p e n} \\
& C_{\mathrm{var}}=C_{e n}+C_{d}
\end{aligned}
$$

where $C_{f}$ is the fixed cost in $\$, C_{\mathrm{var}}$ is the variable cost in $\$ / \mathrm{kWh}, C_{p e n}$ is the penalty cost from the grid in $\$, C_{e n}$ is the energy cost in $\$ / \mathrm{kWh}, C_{d}$ is the battery degradation cost in $\$ / \mathrm{kWh}$.

The annual fixed costs of V2G and IL are \$ 90 and \$ 25 per vehicle [5]. Suppose that the efficiencies of charging and discharging are both 0.92 as suggested in [6], a PEV needs to be filled with $1.18 \mathrm{kWh}$ to realize discharging $1 \mathrm{kWh}$ back to the grid. If the electricity price is $\$ 0.1 / \mathrm{kWh}$, then $C_{e n}$ is $\$ 0.118 / \mathrm{kWh}$ for each $\mathrm{kWh}$ back to grid. Additionally, the energy losses will not increase when only the charging process is controlled. The charging method will pose significant impact on the battery degradation [7]. The degradation cost of regulation services will be lower because of the shallow type cycling. The degradation cost is $\$ 0.0201 / \mathrm{kWh}$ and $\$ 0.0645 / \mathrm{kWh}$ for regulation and spinning reserve services, respectively. Therefore, the $C_{\mathrm{var}}$ is $\$ 0.138 / \mathrm{kWh}$ and $\$$ $0.183 / \mathrm{kWh}$ for these two $\mathrm{A} / \mathrm{S}$. In the IL mode the PEV charging will be controlled to switch on or off which has limited impacts on the life of batteries [8]. Therefore, the variable cost in the IL pattern is ignored.
If the PEV fail to comply with the given command from the grid operator, the penalty would be imposed. The contract of penalty type proposed in this paper is to multiply the penalty coefficient with the potential returns for the PEV provide A/S. The penalty can be represented as follows:

$$
C_{P \mathrm{en}}=r_{0} \times \alpha_{P e n}
$$

Where, $C_{P \mathrm{en}}$ is the penalty cost in $\$, r_{0}$ is the potential revenue which is composed of capacity profit and energy profit in $\$, \alpha_{P e n}$ is the penalty coefficient.

\section{B. Calculation of the Benefit}

The revenue of the PEV owners are composed of two components: (a) a contract payment for availability (in $\$ / \mathrm{kW}-\mathrm{h}$ ) and (b) an energy payment per kWh when dispatched during the $\mathrm{A} / \mathrm{S}$. The revenue is calculated as:

$$
r=p_{\text {cap }} \times P_{\text {con }} \times t_{\text {con }}+p_{\text {energy }} \times E_{\text {energy }}
$$

where, $r$ is the total revenue in $\$, p_{c a p}$ is the capacity price in $\$ / \mathrm{kW}-\mathrm{h}, P_{c o n}$ and $t_{c o n}$ are the CPC $(\mathrm{kW})$ and CPT $(\mathrm{h})$ respectively, $p_{\text {energy }}$ is the market selling price in $\$ / \mathrm{kWh}$, $E_{\text {energy }}$ is the dispatched energy in $\mathrm{kWh}$.

In the V2G pattern, PEV owner will sign rated power with the grid to obtain more revenue. While in the IL mode, the power is limit on the used energy divided by the time it is filled. The power capacity of the IL mode $P_{I L}$ is calculated as

$$
P_{I L}=\frac{\left(1-S O C_{i}\right) \times E_{b a t}}{t_{\text {plug }} \times \eta_{\text {ch ar }}}
$$

where, $S O C_{i}$ is arrival SOC, $E_{b a t}$ is the battery capacity, $t_{\text {plug }}$ is the plug-in duration, $\eta_{c h \text { ar }}$ is the charging efficiency.

\section{CASE STUDY}

In this section we will calculate the annual net revenue of $\mathrm{PEV}$ owners to provide $\mathrm{A} / \mathrm{S}$ in different modes. The revenue under the expected value and considering the uncertainties of driving behavior are both calculated for comparisons.

Based on our previous work [9], the arrival SOC and the arrival time of private PEVs comply with the normal distribution $N\left(0.6,0.1^{2}\right)$ and $N\left(19,1.5^{2}\right)$ in Beijing, respectively. The expected departure time is 7 am in the next morning. We only calculate the revenue in workdays because driving behavior at weekend is quite different from that on workdays. So, only 250 days are taken into account per year.

\section{A. Average values}

In average value scenario, the uncertainties of customer driving behavior are ignored. It is assumed the arrival SOC and arrival time of PEVs are average values every day. The average plug-in time is $12 \mathrm{~h}$. In IL mode, the CPC is $1.15 \mathrm{~kW}$.

We define the dispatch ratio to calculate the dispatched energy $E_{d i s p}$ :

$$
R_{d}=\frac{E_{\text {disp }}}{P_{\text {disp }} \times t_{p l u g}}
$$


where, $R_{d}$ is the ratio defined by the energy dispatched $E_{\text {disp }}$ $(\mathrm{kWh})$ as a proportion of dispatching power capacity $P_{\text {disp }}$ $(\mathrm{kW})$ and plug-in time $t_{\text {plug }}(\mathrm{h})$.

The actual regulation data from PJM are sampled every 4 min during July 18-22 in 2011. The $R_{d \text {-up }}$ and $R_{d \text {-down }}$ are 0.033 and 0.062 , respectively. For the regulation down services, a specific time period should be reserved. The average reserved time is $1.83 \mathrm{~h}$. A PEV can be charged to respond the grid commands, as a result, the reserved time is assumed to be $1.5 \mathrm{~h}$. The operation data in PJM in 2004 are regulation up and down are both $\$ 0.02 / \mathrm{kW}-\mathrm{h}$, spinning reserve is $\$ 0.007 / \mathrm{kW}-\mathrm{h}$ [4]. The results are shown in Table I.

The results indicate that PEV owners providing the regulation down services can obtain maximum net revenue. The maximum total revenue occurs in the $\mathrm{V} 2 \mathrm{G}$ mode providing regulation up services, however, the costs in this pattern are relative high. Providing the regulation services is more profitable because of the higher capacity price.

B. Considering the uncertainties of the customers driving pattern

In this section the revenue of PEV owner signed the contract with average value are investigated. The Monte Carlo simulation method is employed to sample the daily arrival used for calculating the spinning reserve. The $p_{c a p}$ for

SOC and arrival time. The results of $\alpha_{P e n}=2$ are shown in Tab. II.

The results indicate that when uncertainties of driving behaviors are considered, the actual revenue of PEV owner decreases because of the penalty. The penalty cost of regulation down is the highest. For spinning reserve, the utilization rate within a year is less than regulation services. Additionally, for the PJM-RTO data in 2004, the spinning reserve services occurred mostly during the early morning. Thus the penalty costs to participate in the spinning reserve services are low.

Sensitivity analyses are carried out on net revenue to the penalty coefficient. The results are shown in Fig. 1. $\alpha_{P e n}=1$ means no further penalty except for the suspension of the original payment. The sensitivity analysis results indicate that with the increasing penalty factors, the net revenue of participating in regulation down services decreases quickly. When no penalty costs are posed on electric vehicles, the annual net profit is about $\$ 386.9$. The value decreases to $\$$ 160.26 when $\alpha_{P e n}=5$. In addition, the net profit of participating in regulation down services equals to that of regulation up services by $\mathrm{V} 2 \mathrm{G}$ when penalty coefficient is 3.43 .

TABLE I

ANNUAL REVENUE OF CUSTOMER TO PROVIDE A/S IN THE EXPECTED VALUE OF DRIVING BEHAVIOR

\begin{tabular}{|c|c|c|c|c|c|}
\hline \multirow[b]{2}{*}{ Participate pattern } & \multicolumn{2}{|c|}{ Regulation up } & \multirow[t]{2}{*}{ Regulation down } & \multicolumn{2}{|c|}{ Spinning reserve } \\
\hline & IL & V2G & & $\mathrm{IL}$ & V2G \\
\hline Contracted power capacity $(\mathrm{kW})$ & 1.15 & 7 & 7 & 1.15 & 7 \\
\hline Contracted time duration ( $\mathrm{h}$ /year) & 3000 & 3000 & 2625 & 3000 & 3000 \\
\hline Dispatched energy $(\mathrm{kWh} /$ year) & 113.85 & 693 & 1139.25 & 1.16 & 7.58 \\
\hline Capacity revenue (\$/year) & 69 & 420 & 367.5 & 24.15 & 147 \\
\hline Energy revenue (\$/year) & 11.39 & 69.3 & 113.93 & 0.12 & 0.76 \\
\hline Total revenue (\$/year) & 80.39 & 489.3 & 481.43 & 24.27 & 147.76 \\
\hline Fixed cost (\$/year) & 25 & 90 & 25 & 25 & 90 \\
\hline Variable cost (\$/year) & 0 & 95.63 & 0 & 0 & 1.39 \\
\hline Total cost (\$/year) & 25 & 185.63 & 25 & 25 & 91.39 \\
\hline Net revenue (\$/year) & 55.39 & 303.67 & 456.425 & -0.73 & 56.37 \\
\hline
\end{tabular}

TABLE II

ANNUAL REVENUE OF CUSTOMER TO PROVIDE A/S CONSIDERING THE UNCERTAINTIES OF THE DRIVING BEHAVIOR $\left(\alpha_{P e n}=2\right)$

\begin{tabular}{|c|c|c|c|c|c|}
\hline- & \multicolumn{2}{|c|}{ Regulation up } & Regulation down & \multicolumn{2}{|c|}{ Spinning reserve } \\
\hline Participate pattern & IL & $\mathrm{V} 2 \mathrm{G}$ & - & IL & $\mathrm{V} 2 \mathrm{G}$ \\
\hline Contracted power capacity $(\mathrm{kW})$ & 1.15 & 7 & 7 & 1.15 & 7 \\
\hline Contracted time duration ( $\mathrm{h} /$ year) & 3000 & 3000 & 2625 & 3000 & 3000 \\
\hline Dispatched energy (kWh/year) & 69 & 420 & 367.5 & 24.15 & 147 \\
\hline Capacity revenue (\$/year) & 102.46 & 690.98 & 1010.1 & 0.94 & 4.9 \\
\hline Energy revenue (\$/year) & 10.25 & 69.098 & 101.01 & 0.094 & 0.49 \\
\hline Total revenue (\$/year) & 79.25 & 489.1 & 468.51 & 24.24 & 147.49 \\
\hline Fixed cost (\$/year) & 25 & 90 & 25 & 25 & 90 \\
\hline Variable cost (\$/year) & 0 & 95.36 & 0 & 0 & 0.9 \\
\hline Penalty cost (\$/year) & 5.15 & 31.33 & 113.22 & 0.2 & 1.29 \\
\hline Total cost (\$/year) & 30.15 & 216.49 & 138.22 & 25 & 92.19 \\
\hline Net revenue (\$/year) & 49.1 & 272.41 & 330.29 & -0.76 & 55.3 \\
\hline
\end{tabular}




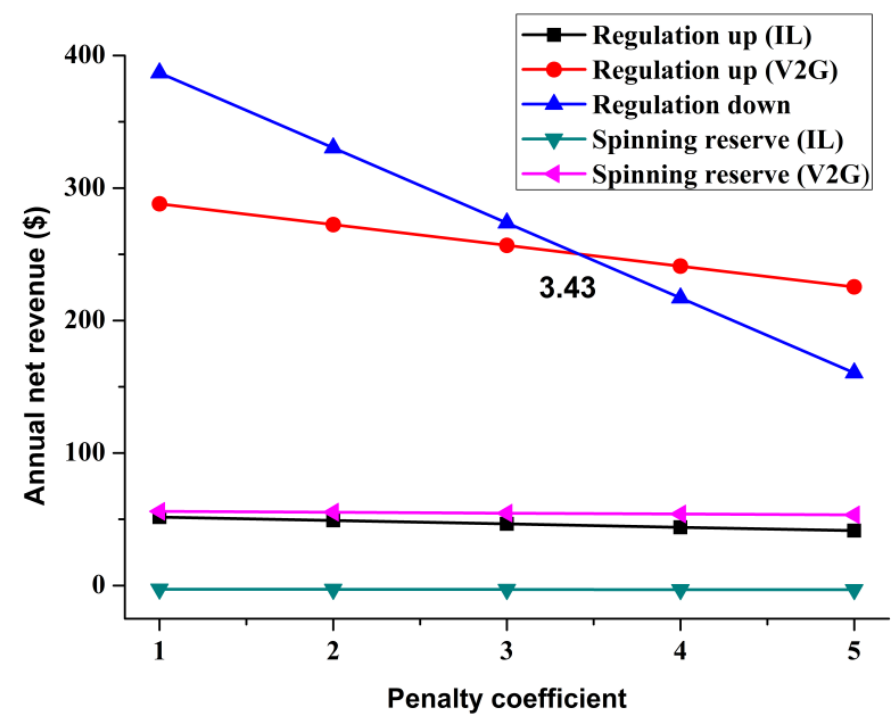

Fig.1 Net revenue sensitivity to the penalty coefficient

\section{CONCLUSION}

The article investigates the revenue of providing $\mathrm{A} / \mathrm{S}$ in different modes. The frequency regulation services are divided into two categories, i.e. regulation up and regulation down services. IL and V2G patterns are first introduced to provide the regulation up and spinning reserve services. Additionally, the expected profits and profits of providing the $\mathrm{A} / \mathrm{S}$ when considering the uncertainties of driving behaviors are both calculated and compared.

The calculation results indicate that profits of participating in frequency regulation are higher than that of reserve services. When penalty is neglected or the penalty coefficient is low, the revenue of regulation down services is relatively high. However, with the increasing of penalty factor, the profits decrease dramatically. When the penalty coefficient is sufficiently high, participating in regulation up services in V2G mode is most profitable.

\section{ACKNOWLEDGMENTS}

This work is supported by National High Technology Research and Development Program of China (863 Program, 2011AA05A110); Projects of National Natural Science Foundation of China (51107060), State Grid Corporation of China and China Southern Power Grid.

\section{REFERENCES}

[1] W. Kempton, S. E. Letendre. "Electric vehicles as a new power source for electric utilities," J. of Power Sources. 1997, 2(3): 157-175.

[2] W. Kempton, J. Tomic. "Vehicle-to-grid power implementation: From stabilizing the grid to supporting large-scale renewable energy," J. Power Sources, 2005, 144(1): 280-294.

[3] W. Kempton, A. Dhanju. "Electric vehicles with V2G: storage for largescale wind power," Windtech International, 2006, 2(1): 18-21.

[4] W. Kempton, J. Tomic. "Vehicle-to-grid power fundamentals: Calculating capacity and net revenue," J. Power Sources, 2005, 144(1): 268-279.

[5] J. Tomic, W. Kempton, "Using fleets of electric-drive vehicles for grid support,” J. Power Sources, 2007, 168(2):459-468.

[6] S. B. Peterson, J. F. Whitacre, J. Apt. "The economics of using plug-in hybrid electric vehicle battery packs for grid storage," J. Power Sources,
2010, 195(8): 2377-2384.

[7] C. D. White, K. M. Zhang. Using vehicle-to-grid technology for frequency regulation and peak load reduction. J. Power Sources.2011, 196(8):3972-3980.

[8] S. B. Petersona, J. Apt, J. F. Whitacre. Lithium-ion battery cell degradation resulting from realistic vehicle and vehicle-to-grid utilization. J. Power Sources. 2010, 195(8): 2385-2392.

[9] Zhuowei Luo, Yonghua Song, Zechun Hu, Forecasting Charging Load of Plug-in Electric Vehicles in China. //Proceedings of IEEE Power \& Engineering Society General Meeting, July 24-29, 2011, Detroit, U.S.A.: $1-8$.

\section{BIOGRAPHIES}

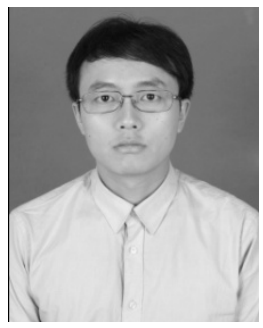

Zhuowei Luo was born in May 1984. He received his M.S. degree in 2008 at Hunan University, Changsha, China. He is pursuing his Ph.D. degree in the Department of Electrical Engineering at Tsinghua University (THU), Beijing, China. He is a member of the team working on Smart Grid Operation and Optimization Laboratory (SGOOL) at Tsinghua University. His fields of interest include electric vehicles and power systems modeling and operations.

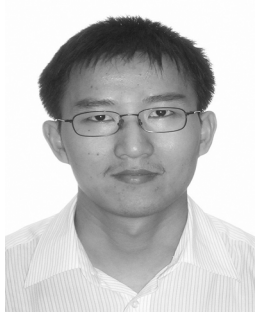

Zechun Hu (M'09) was born in Nanjing, China. He received the B.S. degree and Ph.D. degree from Xi'an Jiao Tong University, Shaanxi, China, in 2000 and 2006, respectively. He worked in Shanghai Jiao Tong University after graduation and also worked in University of Bath as a research officer from 2009 to 2010. He joined the Department of Electrical Engineering at Tsinghua University in 2010 where he is now an associate professor. His major research interests include optimal planning, operation of power systems and electric vehicles.

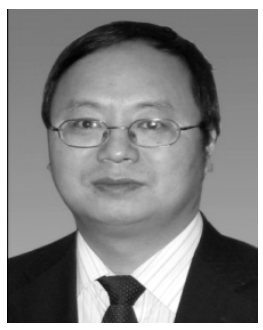

Yonghua Song was born in January 1964. He received his BEng and $\mathrm{PhD}$ from Chengdu University of Science and Technology, and China Electric Power Research Institute in 1984 and 1989 respectively. He was a Postdoctoral Fellow at Tsinghua University from June 1989 to March 1991. He then held various positions at Bristol University, Bath University and John Moores University from 1991 to 1996. In January 1997, he was appointed Professor of Power Systems at Brunel University where he was Pro-Vice Chancellor for Graduate Studies from August 2004. In 2002, he was awarded DSc by Brunel University for his original achievements in power system research. In 2004, he was elected Fellow of the Royal Academy of Engineering (UK). In January 2007, he took up a Pro-Vice Chancellorship and Professorship of Electrical Engineering at the University of Liverpool. In 2008, he was elected Fellow of the Institute of Electrical and Electronics Engineers (USA). He returned to Tsinghua University in February 2009 as a Professor at the Department of Electrical Engineering. In April 2009, he was appointed Assistant President of the University and Deputy Director of the Laboratory of Low-Carbon Energy. In June 2009, he was elected Vice-President of Chinese Society for Electrical Engineering (CSEE) and appointed Chairman of the International Affairs Committee of the CSEE. His research areas include Smart Grid, electricity economics, and operation and control of power systems.

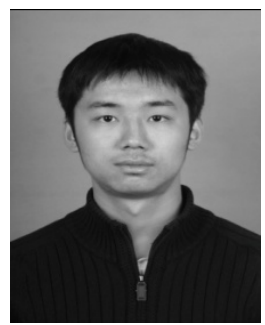

Zhiwei Xu was born in August 1989. He is currently a Ph.D. candidate in Department of Electric Engineering at Tsinghua University. He works in the Smart Grid Operation and Optimization Laboratory (SGOOL) as a research assistant. Zhiwei's research interests include electric vehicles and power systems modeling and operations. 


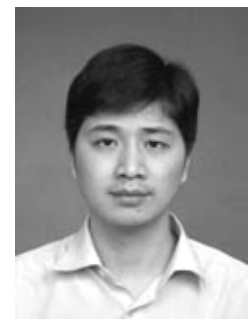

Hui Liu was born in Sichuan, China. He received the M. S. and Ph.D. degrees from the college of electrical engineering, Guangxi University, China, in 2004 and in 2007, respectively. Currently, he is pursuing the postdoctoral research in the department of electrical engineering, Tsinghua University, China. Also, he is an associate professor of school of electrical and information engineering, Jiangsu University, China. His research interests include power system control and electric vehicles.

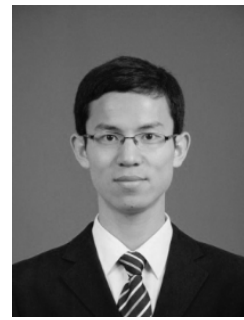

Long Jia was born in Oct 1988. He received his Bachelor's degree in 2011 and is pursuing his Ph.D. degree in the Department of Electrical Engineering at Tsinghua University (THU), Beijing, China. He is a member of the team working on Smart Grid Operation and Optimization Laboratory (SGOOL) at Tsinghua University. He is also an IEEE student member. His fields of interest include power system modeling and operations and electric vehicles.

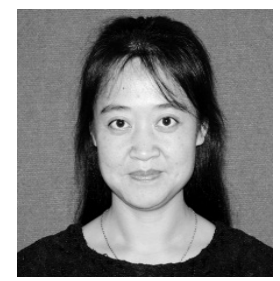

Haiyan Lu received her BEng and MEng from the Harbin Institute of Technology China in 1985 and 1988, respectively. She received $\mathrm{PhD}$ in Engineering from the University of Technology, Sydney (UTS), Australia in 2002. She is currently with the Faculty of Engineering and Information Technology, UTS, Australia. She has published over 50 refereed journal and conference papers. Her research interests include numerical modeling and simulation of magnetic materials for smart electromagnetic devices, optimization methods, forecasting methods and recommender systems and their applications in power systems, power markets and smart grids. 